\title{
SYSTEMS APPROACH TO DOCUMENT MANAGEMENT
}

\author{
Author(s) / Auteur(s) : \\ Nikitas ASSIMAKOPOULOS \\ Professor \\ University of Piraeus, Department of Informatics, Hellenic Society for Systemic Studies (HSSS) \\ assinik@unipi.gr
}

Alexandros MIARIS

Ph.D. Candidate, CSAP Professional

University of Piraeus, Department of Informatics, Hellenic Society for Systemic Studies (HSSS)

amiaris@unipi.gr

Elias SAKELLARIS

CSAP Professional

Hellenic Society for Systemic Studies (HSSS)

eliassakel@gmail.com

\begin{abstract}
Résumé :
The scientific field of Document Management within companies and organizations is very important and in this paper is delivered a systemic approach in both theoretical and empirical level. The study consists of two stages; first is the theoretical analysis of document management and systems and second is the empirical approach by developing and implementing specific strategic and operational planning in a real document management project.
\end{abstract}

In the first stage the definitions of Administration (Management) and Document and the approach the Document Management theories are analyzed. Subsequently, the concept of document management, highlighting the benefits and other elements which made it historically significant and operationally necessary are presented.

In the second stage a specific document management project is presented aiming to create an electronic library using document management systems (DMS). Examples of working libraries are illustrated, using DMS in a national and international level. The strategic planning, SWOT \& PESTEL analysis and the operational planning of the project is explained. Additionally, the project management plan follows, showing its four stages, study, design, implementation and delivery.

Specifically in step two, the stakeholders of the project and their relationships with the using the Design and Control Systemic Methodology (DCSYM) are depicted and the implementation of the project through the development of dynamic simulation of an intelligible model using VENSIM software, representing the main production process followed by a detailed model presentation.

The alternative design is projected, given that the project could not be completed with the characteristics given, followed by the development and implementation of the research. The aim here is the assumption of the projects' problems by the stakeholders contribution and the determination of them in the management structure level.

Keywords / Mots-clés :

Systemic Methodologies, DCSYM, Document Management, System Dynamics 


\section{Document Management}

Document Managemetn is consisted of two major sections, the document itself and the management.

\section{Document}

From antiquity to the present, the format of the document has undergone great changes. From the discourse of Phaistos, the world's oldest printed text, and the papyrus of Dervene, Europe's oldest readable "book", to the e-document and book.

There are many definitions of what a document is, some of the most representative follow:

- It is a stock of information content that gives shape and structure to the information and makes it accessible.

- A defined and structured amount of information that can be interchanged and managed as a unit between users and the system.

- According to Sutton, strict document definition is extremely dangerous to organizations as it creates gray areas within the document archive.

- According to Andrea Wharton, the document is simply a container for information that is available for processing.

Important components of the document are the document lifecycle, directly related to the way the document works, its lifetime, and the systemic functioning of its components. Cycle of life is the time when the form or content of the document or both can change (Figure 1).

The systemic creation flow of the document (including valuable information) is as follows:

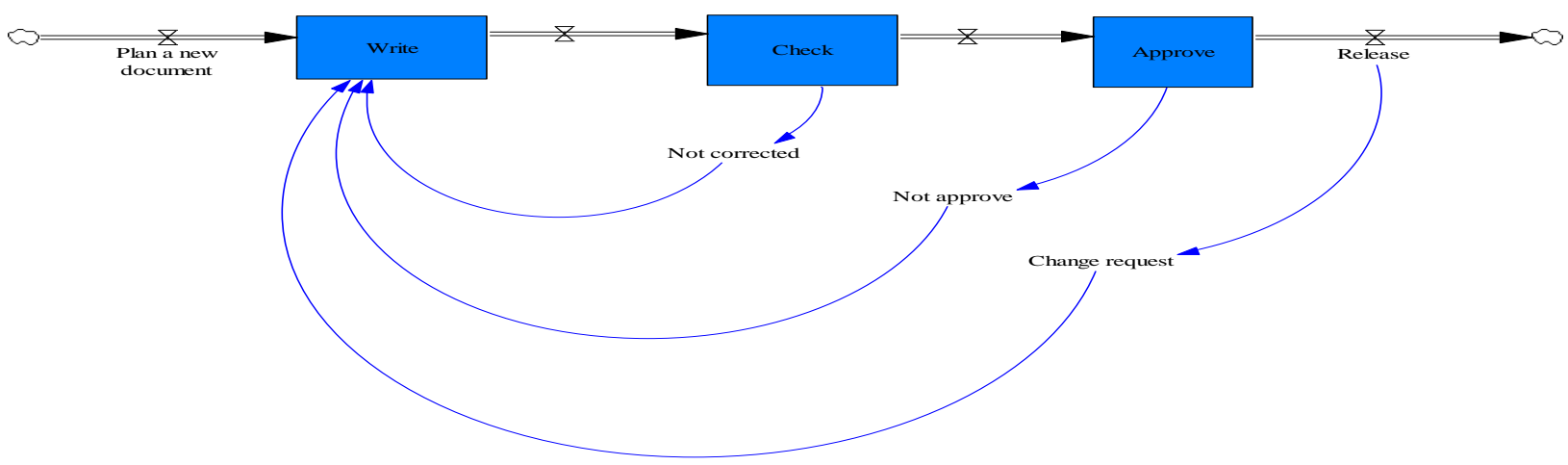

Figure 1 - Document Lifecycle

Initially is the design of a document that contains information which is imprinted in the form of a document. If the information is not accepted, the first feedback will be to get corrected and rewritten. Furthermore the information will be then accepted-approved as information serving the purpose of creating the document. The same process will be once more proceeded until the document id released. The need to change documents is a dynamic and constantly evolving situation due to the high changemutation of the source (Figure 2). 


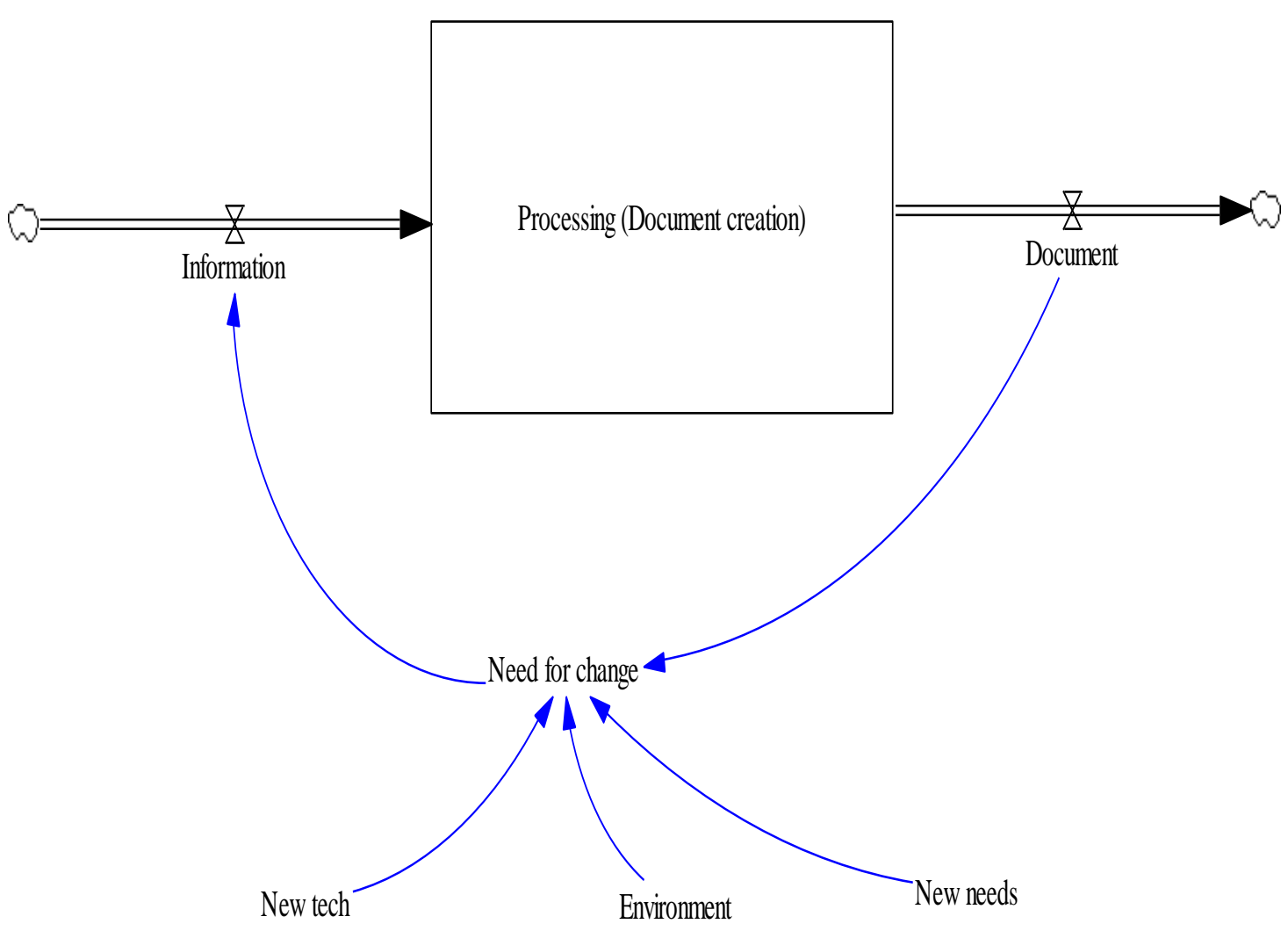

Figure 2 - Evolving information

\section{Management}

The term administration has various definitions, some of which are:

- Management is the coordination and harmonization / integration of all productive resources to achieve concrete results (Kanellopoulos 1990)

- The methodical effort of planning, organizing, managing and controlling activities for the success of specific objectives (Saiti 1992)

- The process of coordinating people and other sources to achieve the organization's goals (Pride, Hughes and Kapoor 1996)

- The process of achieving the goals of an organization by using and utilizing people and other resources of the organization (Certo 1980)

- Administration is the art of achieving the goals through other people (Follett, Smeltzer 1989)

Management is the process of planning, organizing, leading and controlling the limited financial, human, physical, and informational resources of an organization to achieve predetermined goals. The main functions of the management are: Design, Organization, Management and Control.

The theory of administration developed and evolved over the centuries, creating various "schools" of thought (Figure 3). 


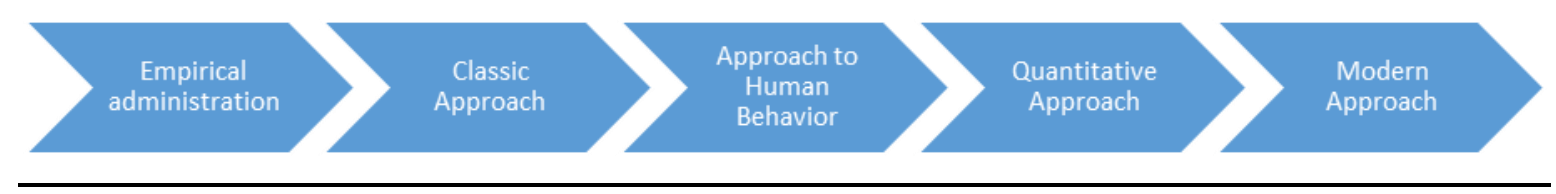

Figure 3 - Management Theories

\section{Theories of Management}

$\begin{array}{ll}\text { i. } & \text { Empirical Administration } \\ \text { ii. } & \text { Classical Administration } \\ \text { iii. } & \text { Behavioral Theories } \\ \text { iv. } & \text { Quantitative Approach } \\ \text { v. } & \text { Modern Approach }\end{array}$

\section{Document Management}

Document management is used, embodied and included in both document and management theories. Document Management approaches the document as an information content that provides form and structure to information and makes it accessible and editable. An important component of the document is its life cycle, directly related to the way the document works, its lifetime and the systemic function of its components. Managing these is a complex and constantly evolving process. It is the process of planning, organizing, leading and controlling limited resources to achieve predetermined objectives of it. In theory, the term Document Management can be defined as the process of overseeing a company's official business records, decision-making records and transient documents of high importance (Sutton 1996).

Systemic Approach to a Document Management System (DMS)

Systemic thought is a dynamic complexity, was born through the General Systems Theory in 1954 of General Systems Theory (Ludwig von Bertalanffy) as a response to the inadequacy of mechanistic thinking to explain biological phenomena. According to this theory, System is an entity (a set of parts) that preserves its existence (s) through the mutual interaction of its parts.

According to the systemic approach, a document management system (DMS) is a single set that can not be divided into independent parts since the key attributes of a system as a whole derive from the interaction rather than the action of individual parts. This means that if the DDMS breaks down into independent parts, then this system and its parts lose their Basic properties.It is a complex and strongly interconnected network of essential parts exhibiting cooperative properties since the most important is not the sum of these parts but their cooperation as all is more important than the sum of the parties.

It consists of five (rarely and more) essential elements-parts: Scanning, Indexing, Storage, Retrieval and Security, these are the the parts of the system without which the system can not and which must meet certain conditions: They may affect the behavior and properties of the whole, they should work together to function, and when the individual parts of the system are organized into subsystems, they have the same properties as the essential parts.

The properties of the DMS are derived from the relationships of its structural parts. If we have improved an individual element, for example Indexing, this does not guarantee the improvement of the entire 
DMS. Generally when the performance of an individual part of the system (regardless of the set) is improved, the performance of the system as a whole remains unchanged or worsens.

Each system is defined by its function (its role) in a larger system. To understand a system, we need to understand its function in the larger system. The DMS has one or more functions - defining function within a larger system, over-system, but also in relation to smaller systems, subsystems. Each DMS is organized in a hierarchy of organized complexity (Figure 4) where each level consists of different systems. It consists of subsystems of less complexity that affect and are affected by our system but it is also a subsystem of a larger hypersystem.

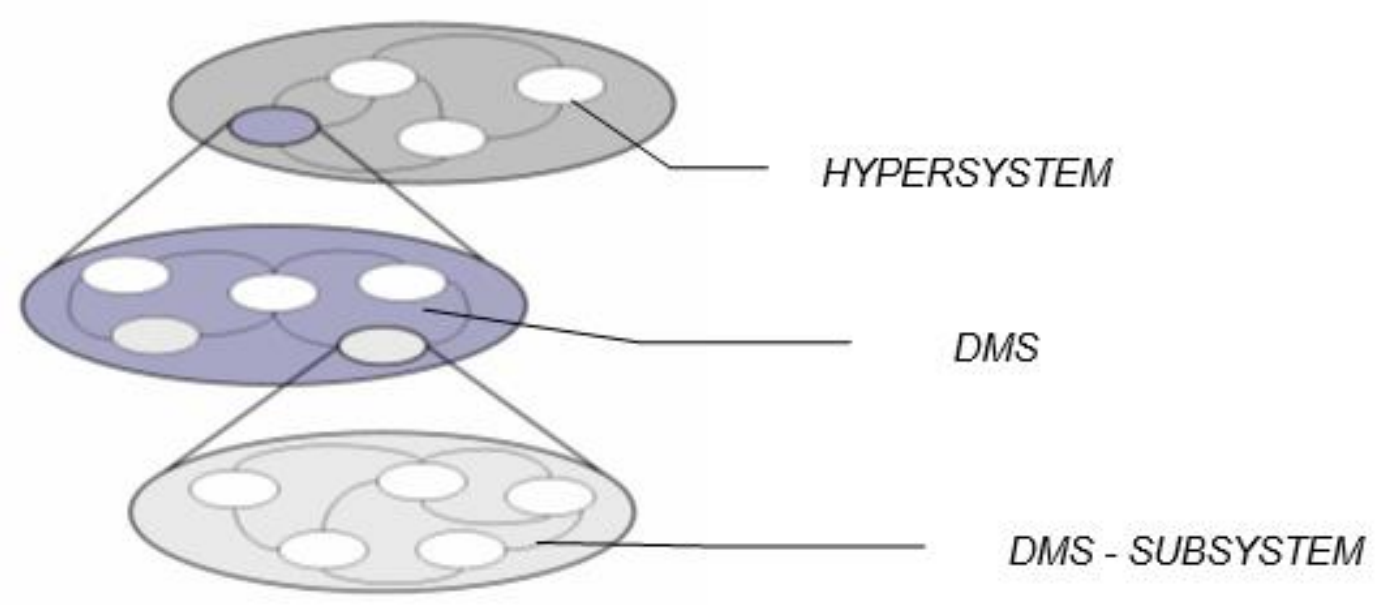

Figure 4 - Hierarchies - Subsystems \& Hyper-Systems

Systems are organized hierarchically,

- A DMS subsystem is part of a larger system and is defined as a subset of its variables.

- The DMS is a piece, subsystem, of a larger system-supersystem containing its definitions.

- All processes at each level are limited and take place according to the laws of the next highest level. Knowing and studying the rules of the individual elements of the system leads to the formation and extraction of the laws governing and explaining the behavior of our system as a whole.

- Each hierarchical level produces new properties that do not exist in the lower levels (Emergent properties).

\section{$2 \quad$ Creating a Digital Library}

The main purpose of libraries is to provide a specific service: access to information. The digital revolution of our society has transformed the traditional tranquil world of libraries, since libraries are now losing their traditional and simplified form. We do not just deal with Conventional Libraries but also with Automated, Electronic-Digital, Hybrid, Virtual and other.

Specific milestones have been made in the development of the Electronic-Digital (E-D) library. We essentially use the term "Digital Library" to describe the case in which the items are stored in electronic rather than printed form. If users prefer it, it is possible to produce printed copies of electronic documents. But the essence of the electronic library lies in the electronic use of the evidence.

There are many examples, at domestic and international level, of successful E-D libraries. In Greece there are important digital libraries such as: 
- Anemis Digital Library of Modern Greek Studies, which was created in the spring of 2006 by the Library of the University of Crete within the framework of the Operational Program "Information Society" and which offers to the Internet user a rich collection of bibliographic information, digitized books and articles Emphasis on Modern Greek culture, 2 million digitized pages of rare books and more recent editions, the authors of which allowed digitization as well as their free Internet.

- The National Documentation Center, which acts as a key player in Information Society content, and develops the Digital Science and Technology Library, which includes online content for all their sectors and provides the user with full search capabilities and retrieval of digital material through open access journals, digitized Greek collections, dictionaries - books, international databases.

- The Digital Library of Ioannis Sikoutris, belonging to the library of the Academy of Athens, Digital Collections of the National Library of Greece, the Digital Library of the Public Central Library of Rethymno, the Digital Library of the Public Central Library of Mytilene, the Digital Library of the Public Central Library of Serres, Digitized literary journals of the National Book Center, and many others.

Also, many Greek universities have created digital libraries to serve the needs of the university community, such as the Panteion University that created "Pandemos", an electronic publishing site for the writing activity of the members of the Panteion University, through which Broad publicity and direct availability, greater visibility and employment in the wider scientific community, scientific communication, And is an online repository that ensures unrestricted open access to the distribution of digital content. The National Kapodistrian University of Athens has developed the Digital Library "Pergamos", which has been developed by the Library Computing Center team and is used for the preservation, documentation, management and promotion of heterogeneous digital collections, which belong to the University of Athens. The University of Patras has also developed the web site "University of Patras, Library and Information Center", where the visitor is provided with a particularly valuable Directory of Greek Digital Resources. The university community in general has a significant role to play in the digitization of cultural material, through the activity of many other Greek Universities, such as Aristotle University of Thessaly, Agricultural University of Athens, Athens University of Economics and Business, University of Piraeus Of Athens and Piraeus, which have created equally valuable online platforms that provide access to members of their educational community in digital collections, electronic journals and books.

At European field, the European Union has manifested its interest in the creation of a European Digital Library, a vision that has been largely achieved by the creation of "Europeana", an online platform already preserving a large part The European cultural heritage. It is a combination of Europe, the Museum and Archives of Europe, closing its fifth birthday, reaching 30 million digital objects, two years before the planned goal. Europeana collects, in a single database, the information that accompanies digital objects and provides a single point of access to the cultural material collected throughout Europe.

Also at a global level there are, The National Library of Germany, the Boston Library, the Harvard Digital Library, the Perseus Digital Library, the Digital Library of Alexandria, the Digital Library of France, "Gallica", The Unesco Digital Library, "World Digital Library" and many other examples. 


\section{Strategic plan}

Strategic planning involves initially developing the strategy through the declaration of vision, mission, and values to be served.

The vision and mission of the project is to create a learning and information area for students and not only on the digital library platform of the University offering easy and direct access to knowledge. More specifically, the project "Digitization of the Library" aims at creating a digitally scanned electronic archive, which will then be processed with the most up-to-date programs in order to have the necessary clarity, the creation of e-books and finally Their documentation. These goals should be: S.M.A.R.T. (SPECIFIC, MEASURABLE, ACHIEVABLE, REALISTIC and TIME BASED that is achieved through project management.

The values to be served are: respect for the personality of individual, integrity and ethos, to be close to the needs of society and the people and not to exceed his expectations, focus on the continuous improvement of quality - functionality, fairness in the treatment of personnel, Decision-making and leadership skills, respect for personal life with balance between personal needs and work requirements, knowledge diffusion and systemic integration.

These define more or less of where we would like to be in the future by shaping strategic planning. It is equally important to determine where we are now so as to know the distance that we will need to cover and close the gap between the now and the ideal future by applying the appropriate methods to achieve this (business planning).

\section{i. $\quad$ SWOT Analysis}

The strengths and weaknesses relate to the company's internal environment as it derives from the internal resources it owns (manager and staff competencies, business qualities and characteristics, know-how, financial health and the ability to respond to new investments).

Opportunities and threats, on the other hand, reflect variables of the enterprise's external environment, which the enterprise will have to identify and adapt wherever possible (entry of new competitors, regulation in the legal environment, Creation and / or emergence of new markets).

The SWOT analysis of the project is presented below (Figure 5) 


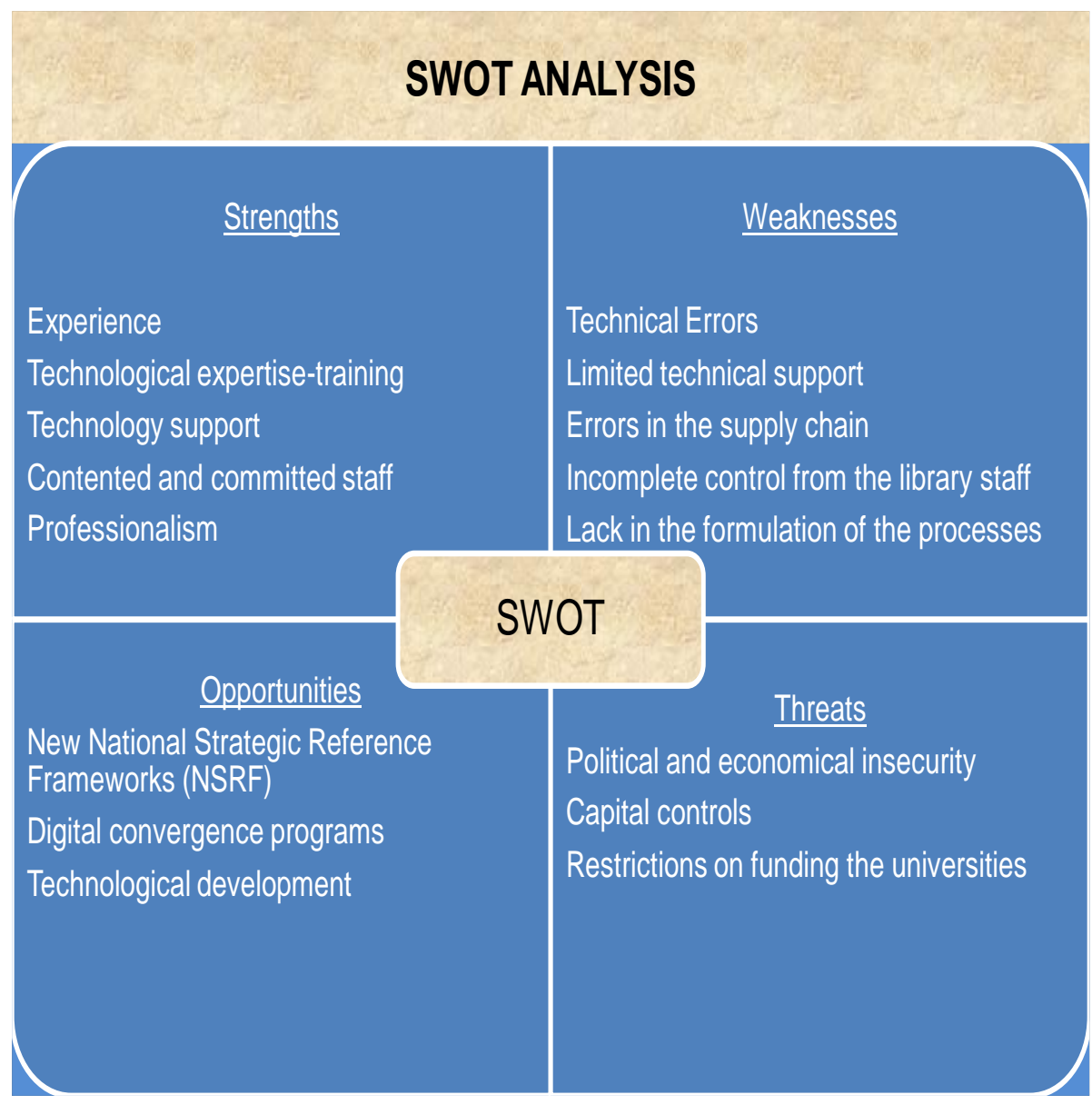

Figure 5 - SWOT ANALYSIS in «Project Digital Library»)

The SWOT analysis identifies the strengths and weaknesses of the strategic stakeholders as well as the project in general. Also, opportunities and threats from the environment are identified and highlighted. More specifically, the above table contains the most important of them, creating the main strategic considerations of the project at the beginning and its overall duration (in the implementation phase we will see what the main strategic options were in terms of strategic considerations and their treatment).

\section{ii. PEST - PESTEL Analysis}

It is also a strategic tool used to analyze the Macro-environment of a business, the systems and structures that surround an enterprise-a project. The PESTEL analysis explores: Political, Economic, Social, Technological, Environmental and Legal-Legislative Frameworks Legal).

- Political environment: political instability, government discontinuity, limited government competition protection policies, high corruption, bureaucracy.

- Economic environment: GDP limitation, declining economy, stagflation, unemployment, high borrowing rates, limitation of borrowing, bureaucracy.

- Social environment: Increased leisure time, mood for education, mood for increased knowledgeskills, tradition of education.

- Technological environment: Increased production of technology products, continuous technological progress, new technological solutions, lower cost products and better quality, innovative products and services. 
- Environmental issues: Increased public interest in environmental issues, identification of technology products with environmental protection.

- Legal environment: independence of justice, bureaucracy, strong legislative framework for the protection of commercial and corporate activities, unlimited law

Here the environment is rather positive towards the work of the digital library on social, technological, environmental and partly legal issues. On the contrary, it faces many economic and political hurdles.

\section{Business Plan}

It covers all the actions and reactions that support and implement strategic planning. In addition, the business plan, in terms of projects, involves the development and implementation of specific projects for the organization, management and execution of projects, ie the development and implementation of a specific project plan.

In general, a project, is a temporary effort we make to create a unique product or service. The projects are executed by people, executed with limited resources, they have a start and an end. They are the main components of the business strategy and its implementation through their management and administration.

Organizations that perform projects usually divide each project into phases to increase control over the project. Cumulatively, these phases of the project, usually four, are the project life cycle (FIGURE 2.5). Each phase ends with the delivery of the phase deliverables. Deliverables aim to complete the product or the services that the project produces.

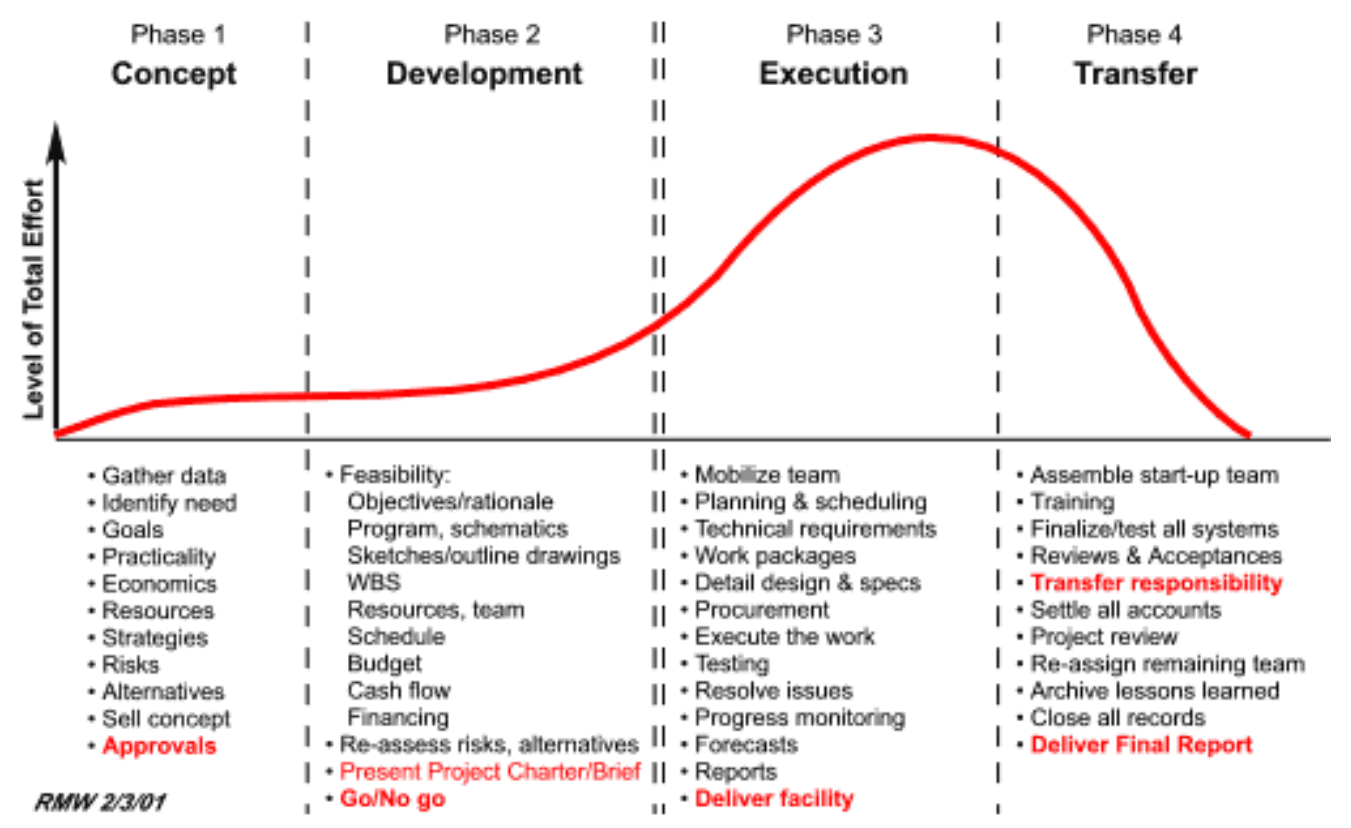

Figure 6 - Project Lifecycle

The life cycle of the project has 4 phases. In the first phase, the project is studied as an idea, its feasibility, size and first processes of organization. The necessary information is few, condensed and involves high administrative levels, and at the same time involves great risk. The first phase ends with the decision whether or not to start the project. The second concerns the study \& design of the project, the effective organization of the project from a technical and financial point of view, budget preparation, staffing, 
timetable. The third phase aims to implement the project's action and implementation plans. Finally, the fourth includes the completion and delivery-transfer of the project. The goal of the project management is to finish the project within the specified time, scope and cost limits.

The implementation of these objectives is achieved through the management of this project and more precisely by the correct identification of the following areas of the project, which essentially describe the methods and techniques of the Project Management, based on its basic processes:

- Managing project integration: Ensures appropriate coordination of the different parts of the project

- Management of the scope of the project: ensures the presence of all the necessary work to complete the project successfully

- Time management: ensures the completion of the project within the specified time constraints

- Human factor management: ensures effective use of the human factor of the project

- Project quality management: ensures that the project's quality constraints are met

- Project Cost Management: Ensures completion of the project within a budget

- Communications Management: ensures the direct creation, collection, transmission, storage and use of project information

- Risk Management: Ensures timely reading and response to project risks

- Supply management: ensures the acquisition of the necessary materials for the project

\section{Project Plan}

The project has four stages.

Stage 1 The purpose of the project is to convert academic titles into e-books, which will be available on the Library's website. The aim of the project is to deliver it within the deadline, the agreed costs and specifications. The project plan, training, monitoring, execution and follow-up took place following the negotiation and co-decision of the project manager of the interested companies - ON SA, EL SA \& University (library)

Stage 2 The aim of the project is to convert 3,700 academic titles into electronic books, which will be available on the Library's website within one hundred (100) working days. Fundamental sources of funding are: University funds available, European support programs as well as funds from Information Technology and Digital Convergence. The main stakeholders and all communication channels between them are identified. 


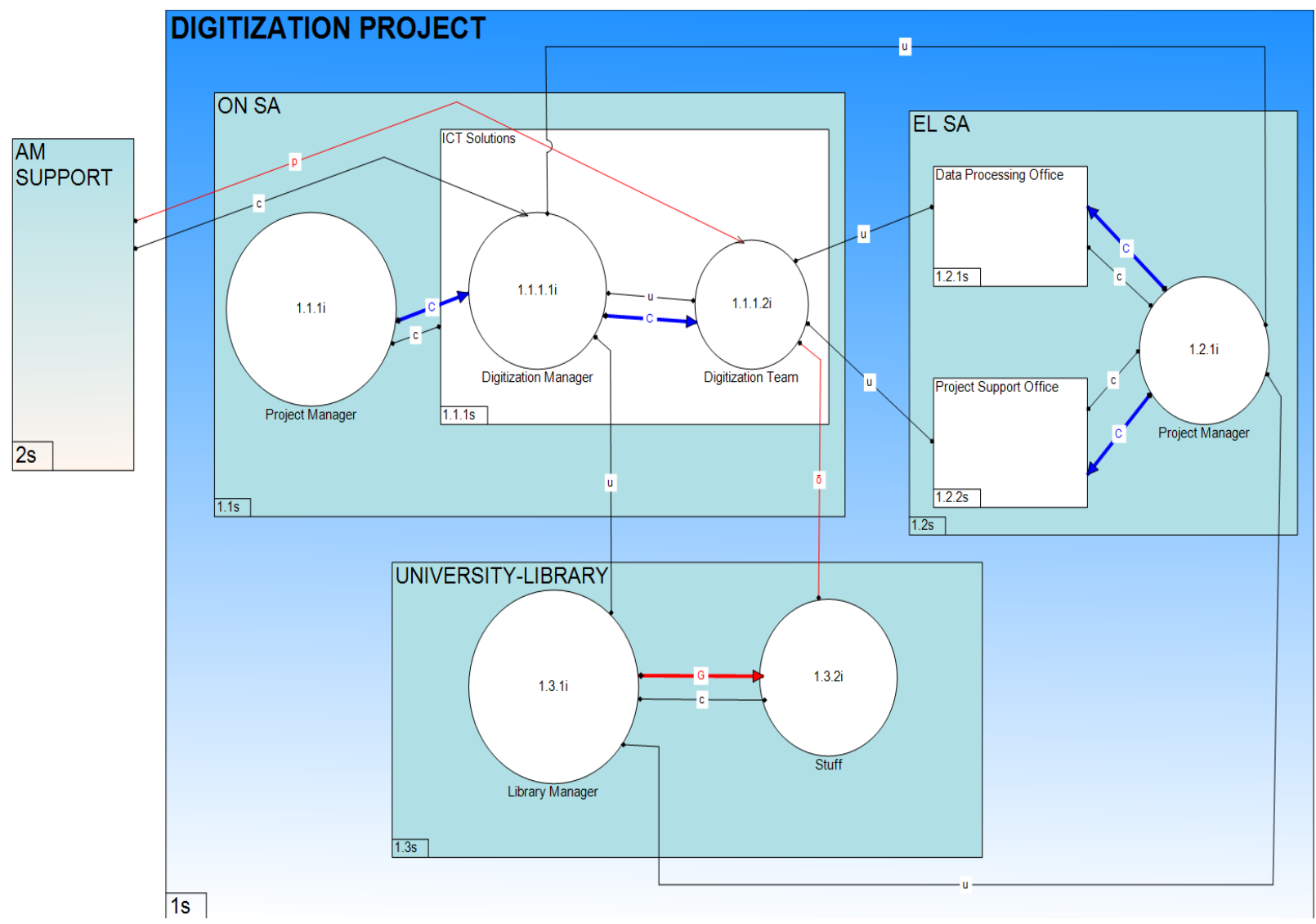

Figure 7 - Stakeholders of the Digital Library Project

Stage 3 It involves defining the processes of the project, identifying the main production process of the project and its implementation through its modeling. Process Definition is the visual representation, the map, of the basic steps of a productive sequence of actions that produce a certain output by having first transformed a previous input.

The SIPOC Diagram (Figure 8) is an excellent tool used by Six Sigma Enhancement Groups to identify all relevant elements (suppliers, inputs, process, customers) of a process-process identification and improvement plan. Visualises summaries of inputs and outputs from one or more processes in a table form. 


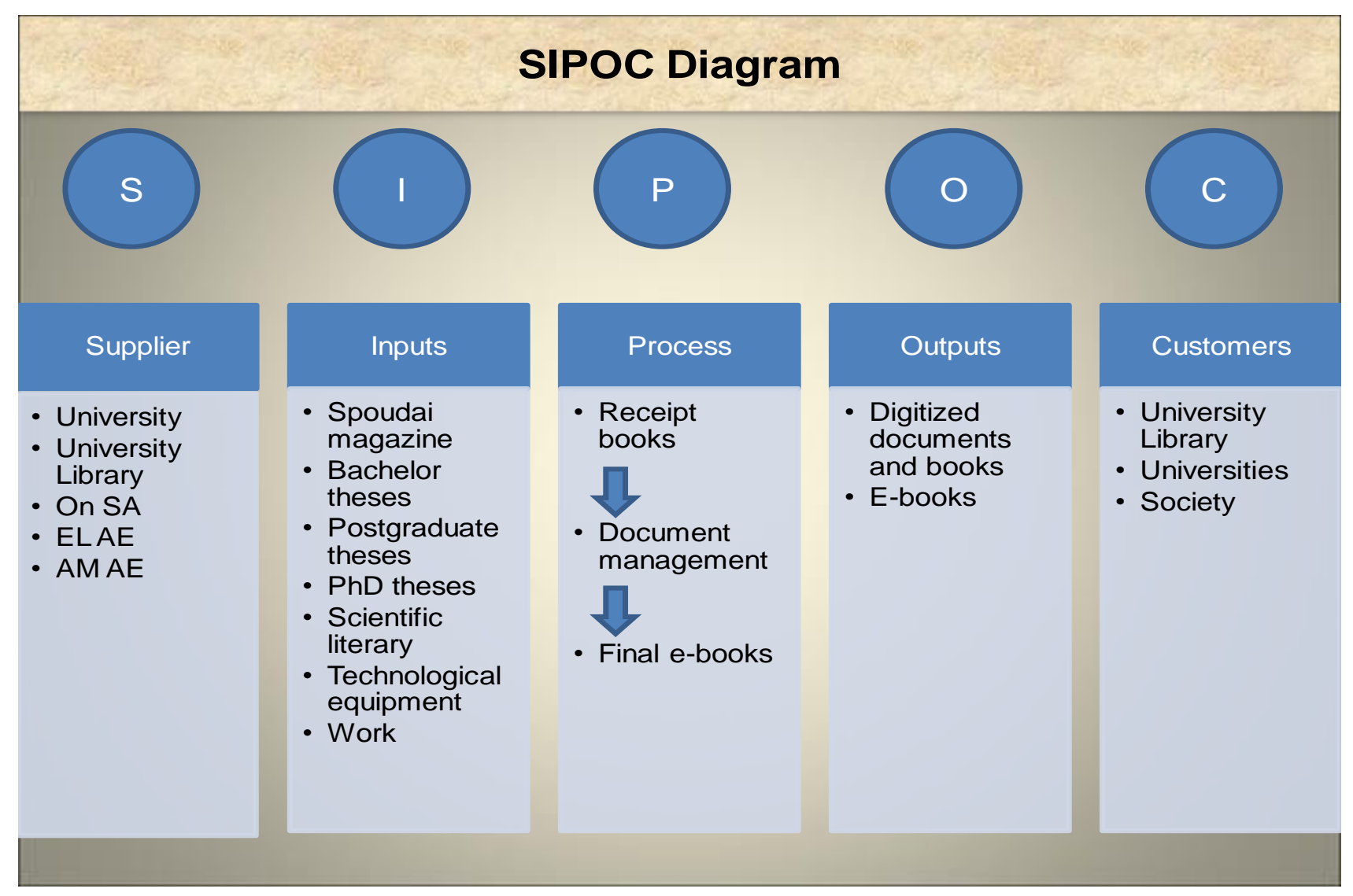

Figure 8 - SIPOC Diagram

The identification of the basic production process (Figure 9), no matter how important it may be, is still a snapshot of the production process. It is extremely useful to achieve the design of an intelligent model that will simulate as accurately as possible the dynamic behavior of an event, phenomenon, system that is being monitored (system in focus). The objective is to create a realistic simulation model. 


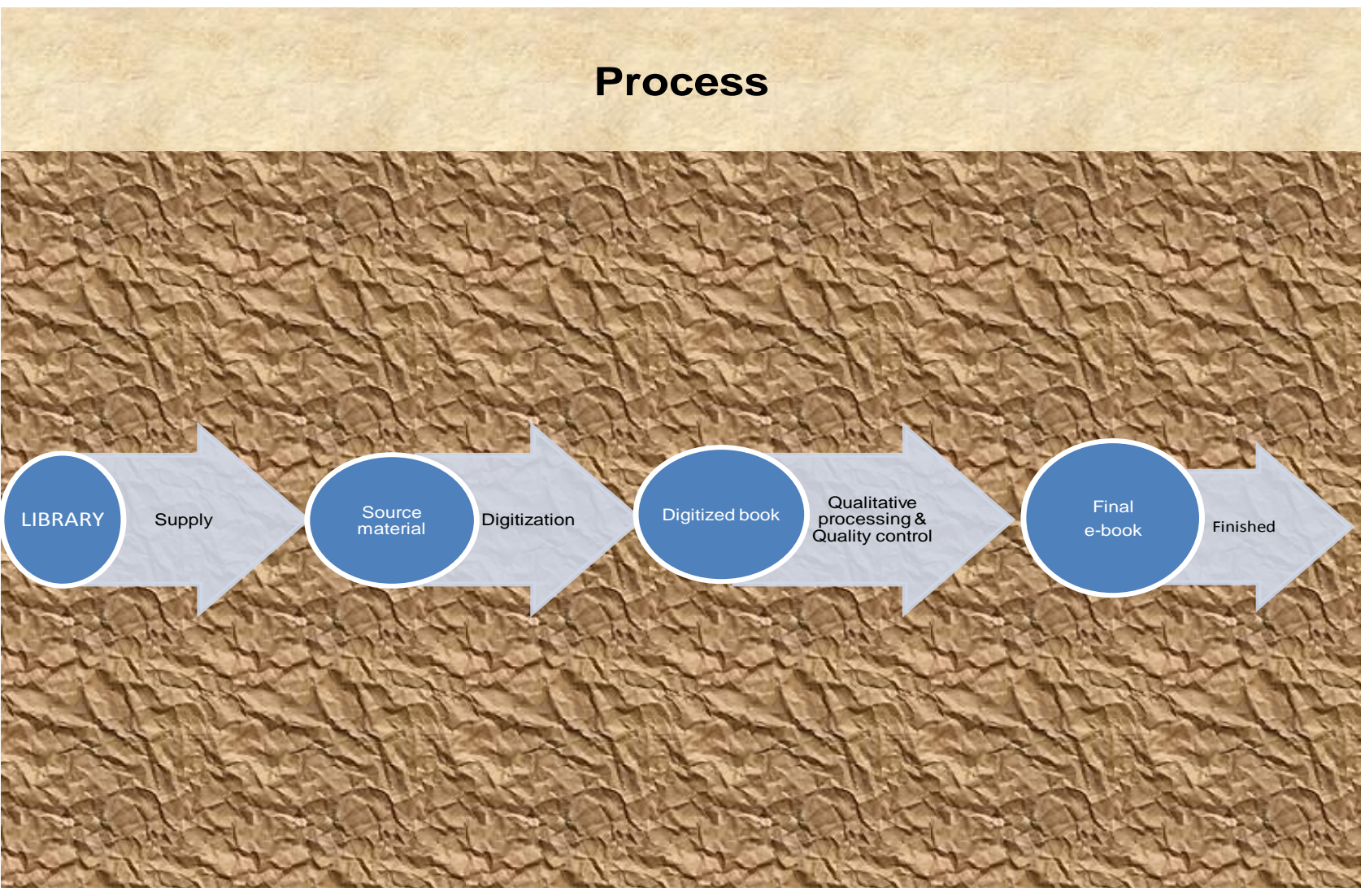

Figure 9 - Main Process in Digital Library

Stage 4 Stage 4 is relevant to the completion and delivery- conclusion of the project, something that is unattainable according to the modeling but also the actual implementation. It is imperative that we develop, build and implement the appropriate feedback plan so that we can successfully complete the project within the limiting factors given to it.

\section{Feedback Plan}

According to the modeling and the actual execution of the project, specific problems have been observed which do not lead to the successful completion of the project.

The main problem is the inability to complete the project within time (on time, 100 days) and requirements (on scope, 3700 e-books). The problems leading to the non-completion of the project were identified, collected and categorized according to the results of the modeling, the actual flow of the project and the opinions of the stakeholders in the project following the collection of data through various questionnaires. The proposed solutions were identified, categorized and ultimately adopted by all stakeholders through the implementation following the Delphi methodology.

The application of the DELHI methodology, under the guidance of the System Analyst, has led stakeholders to consensus on specific solutions to project problems. After the consultations of the project managers, strategic stakeholders and the evaluation of the views they gathered by using the methodology of the DELHIs.

\section{Systemic Changes}


The following is a survey of changes in the structure of the system under consideration (and consequently behavioral change) using DCSYM. The change of structure is targeted and seeks to change its behavior, expecting it to lead the system to fulfill its goals, to complete the project.

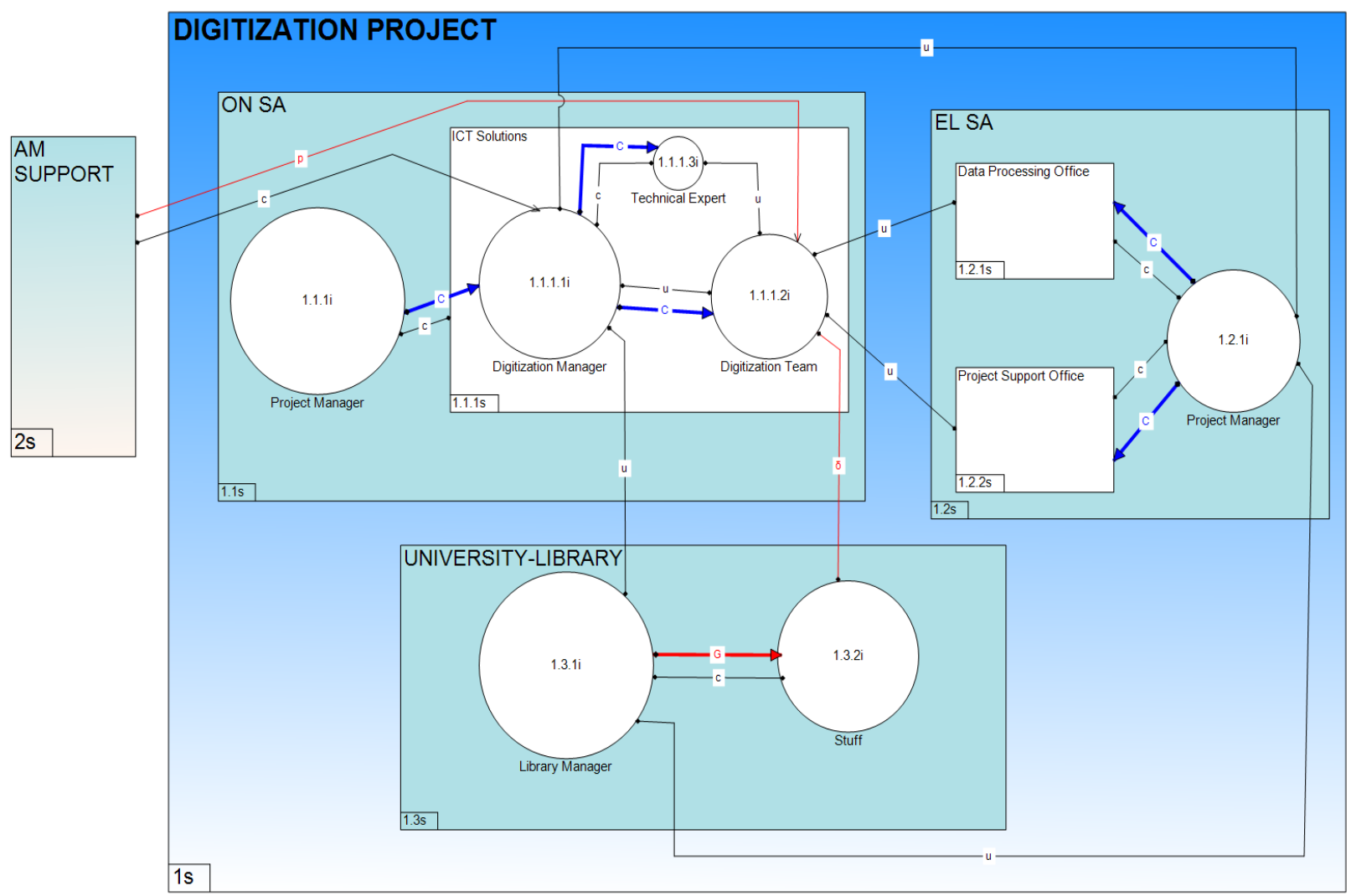

Figure 10 - Systemic Change A

It is depicted (Figure 10) in subsystem 1.1.1s, the recruitment of a technician schematically presented as a person 1.1.1.3i which communicates with individuals 1.1.1.1 and 1.1.1.2i having good (c) and good intentional communication (u ) Respectively. It is controlled by the person 1.1.1.1i. Using good (C) communication.

\section{Quality results of systemic changes}

By hiring a specialized technical scanner

$>$ Increased production through the proper division of labor

$>$ Technical errors were solved directly with minimal effect

$>$ Time losses in the project were limited

$>$ Maintenance has improved the technical performance of the machines, their long-term viability and ultimately the value of the project's capital equipment

$>$ A sense of security was created for the participants in the production

$>$ The moral was raised. 


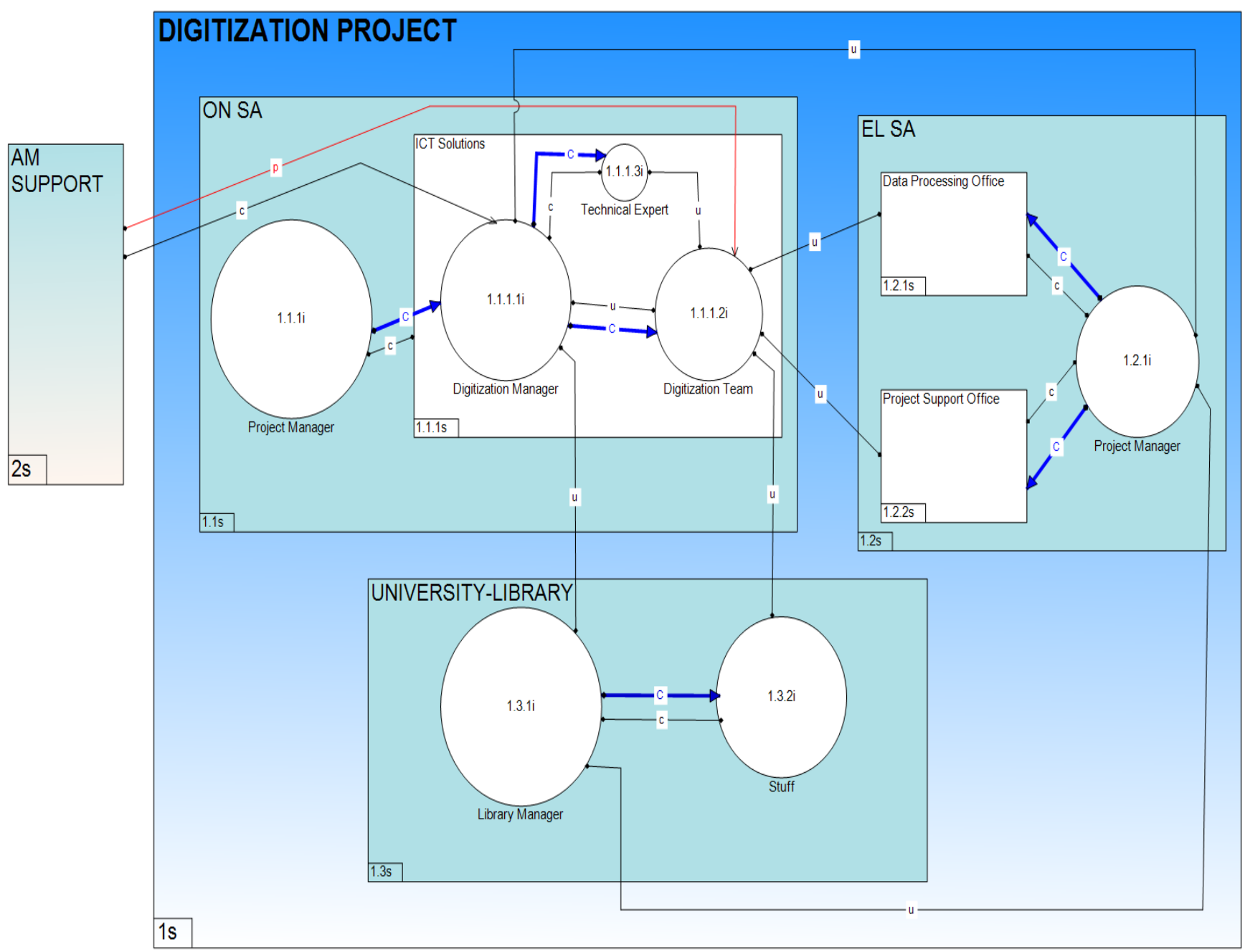

Figure 11 - Systemic Change B

It is depicted (Figure 11), in the 1.3s subsystem, the change of the kind of control of the person 1.3.1i to 1.3.2i from general interaction-influence $(\mathrm{G})$ to good $(\mathrm{C})$, which in turn leads to change the type of communication between individuals 1.3 .2 and 1.1.1.21 by deliberately disturbed communication (d) in good intentional communication $(\mathrm{u})$.

\section{Quality results of systemic changes}

By systematic and pressured control from Library Manager towards the Library Stuff, as well as strictly observing the project timetables

$>$ The errors in the supply of the Digitization Team by the library staff were limited

$>$ The response time of employees was considerably reduced

$>$ Time deviations in the project were limited

$>$ Increased professionalism and formalism in the process

$>$ Production increased

$>$ The communication and collaboration of library staff with digitization has been improved 


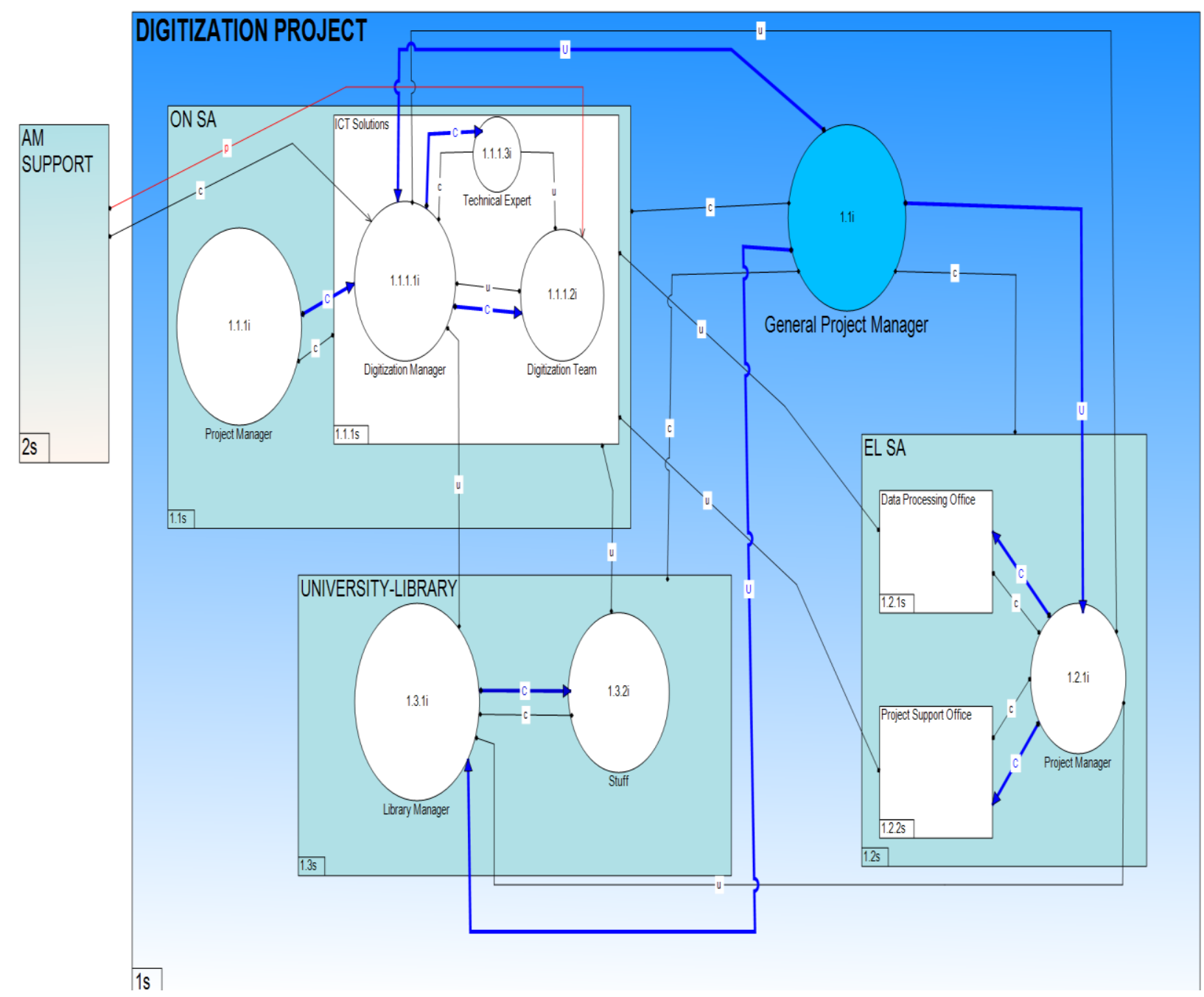

Figure 12 - Systemic Change C

It is depicted (Figure 12), in the 1s system, the creation of the new General Project Management position, which is represented as the $1.1 \mathrm{t}$ person and which has good communication (c) with the $1.1 \mathrm{~s}, 1.2 \mathrm{~s}$ and 1.3s subsystems. It controls individuals 1.1.1.1.1, 1.2.1 \& 1.3.1 using good intentional communication (U).

Quality results of systemic changes

With the creation of the new position, General Project Manager (GPM)

$>$ Improve response times and overall performance of managers and employees

$>$ The errors were reduced

$>$ Improve the results of each party and overall production

$>$ A sense of security and support has been created through continuous animation and regular contact with all parts of the project

$>$ Valuable know-how has been created through the systematic monitoring and recording of the project as a whole. 


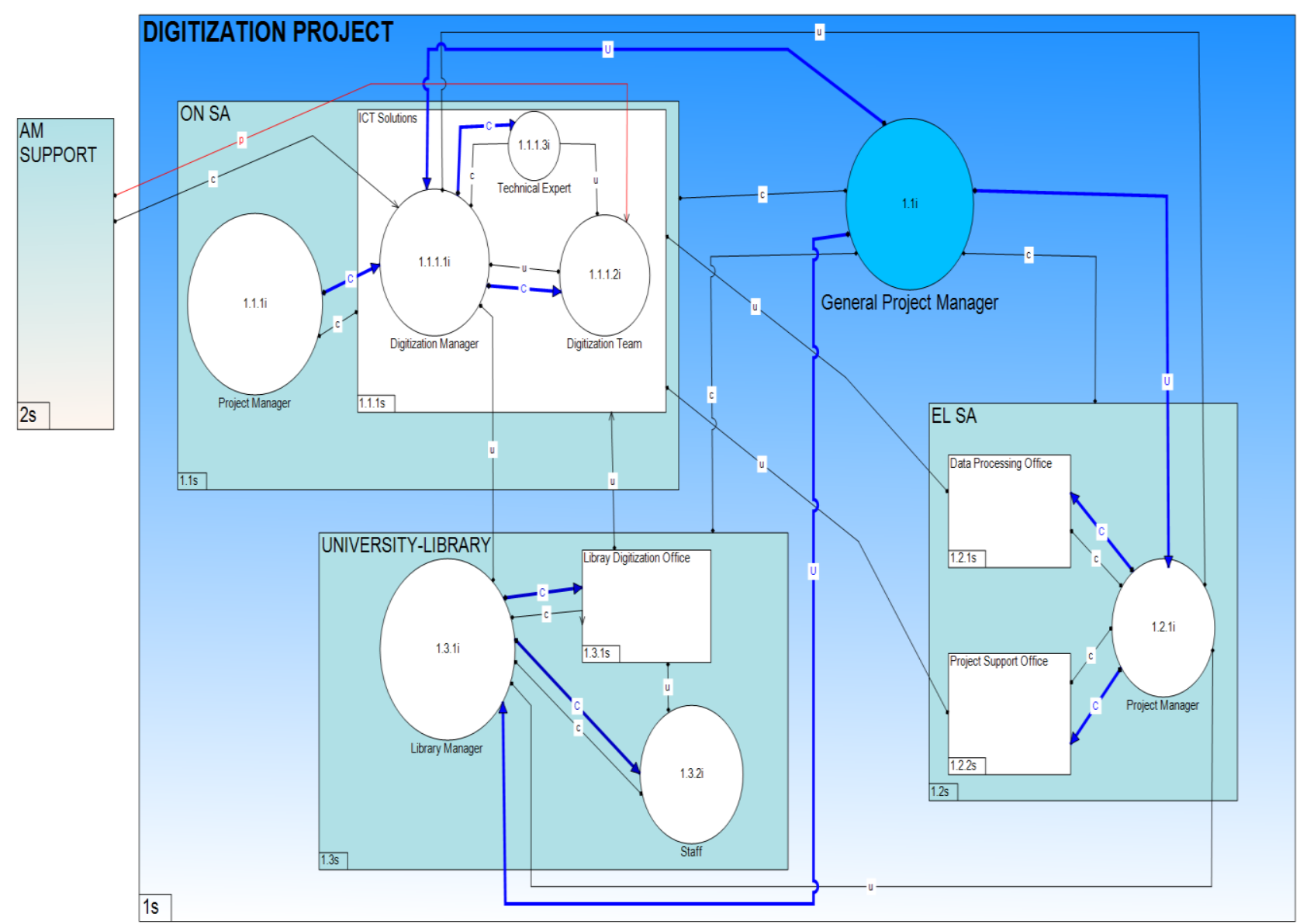

Figure 13 - Systemic Change D

It is depicted (Figure 13), in the 1.3s subsystem, the creation of a new subsystem 1.3.1s which has good communication (c) with the person 1.3.1i and good-intentioned communication $(\mathrm{u})$ with the person 1.3.2i. It is controlled by the person 1.3.1s.

Quality results of systemic changes

By standardizing the processes, in a library and digitizing department, the introduction of SOP and the creation of the Library's special section responsible for digitization will be achieved:

$>$ Improve employee co-operation

$>$ Reduce errors

$>$ Prevention of future variations in production

$>$ Achieve maximization of the efficiency and continuous support of the project. 


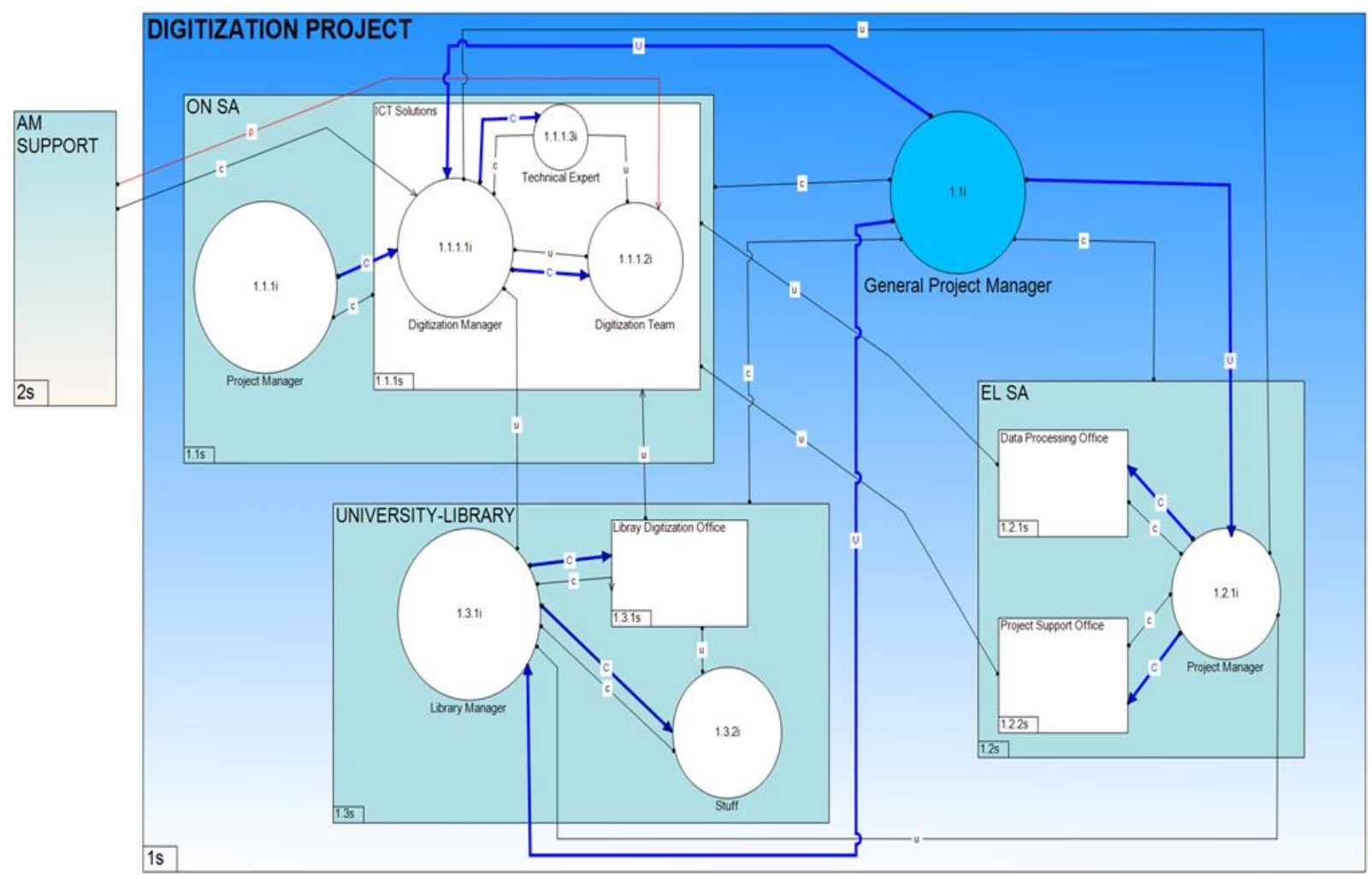

Figure 14 - Overall Systemic Change

The above-mentioned mapping of changes in the structure of the system in focus under consideration leads to a targeted and guided change in behavior by anticipating such results that will eventually lead the system to fulfilling its goals, namely to complete the project.

\section{Conclusions}

The world is changing. Globalization, new economic conditions and technological progress create a more complex environment for people and organizations. It is extremely important for organizations to be able to cope with the new world conditions as they are shaped, but also able to record and decode messages coming from the environment and carrying the most important information necessary for everyone. In the past, the decoding and recording of these messages was quite affordable as the complexity of the environment was lower and it was relatively easy to connect the events and create cause-effect chains to make it possible to interpret the past and, to a great extent, forecast for the future. By increasing complexity, however, as mentioned above, analytical thinking alone did not suffice, necessitating a different holistic approximation of things, systemic analysis.

The ability to locate, decode and record information is the key part of the perpetuation and survival of organizations in this new environment. Initially because they can actually receive information from their environment (open systems) and on the other hand because they can decode it, record it as a document and use it practically. Recording and exploitation, however, requires the ability of organizations to process it properly and to use it by retrieving it easily and quickly. To do this, the Document Management field must be properly used.

The use of Document management has been relatively simple in the past to use and required only cabinets and fasteners. As the years passed away, great technological progress and increased complexity followed. Then became necessary to develop the Document Management field. So the D.M. improved 
by increasing and improving its structural parts. But their function arbitrarily or autonomously strengthened mechanistic logic against the need for systemic approach and integration. The everchanging circumstances and the need for change and the reduction of uncertainty led to the adoption of the systemic approach as it was necessary to address the new problems and those whose creation had come from the wrong solutions we took in the past. Yet yesterday's solutions create the current problems. Thus, Document Management has evolved into System Document Management, which addresses the functional parts of the D.M. as a System (DMS) and these have in turn evolved into "smart" DMS and EDMS.

Document Management has overcome its analytical approach and has seen the relational link of its structural parts that have emerged in the past by mechanical logic. In Mechanistic Thinking (Analytical Method), a system is an assembly of parts in which the total is equal to the sum of the individual parts that make up it. In Systemic Thinking, a System is a complex and strongly interconnected network of parts that display cooperative qualities. The Document Management System is not just a sum of its parts but a set of interactions between themselves but also with the environment they belong to. It is a set of parts which can not be divided into independent parts because the basic properties of the system as a whole derive from the interaction and not from the action of its individual parts. When it is split into independent parts both the system and its parts lose their basic properties (the whole is larger than the sum of the parts).

The use of DCSYM led to the visualization of the project and the determination of the active area of the system under consideration, the system in focus. This leads to the identification of stakeholders as the key parts of the system, to the identification and characterization of the kind of relationships and communications (structural parts). The types of communications and structure also extract the explanatory knowledge of the behavior of the system. The reason the system behaves in the way it behaves is the result of the structure of the system but also of the relations and communications that exist within and between its essential parts and the background. If we want to change the way the work or the system works or the system in focus, we have to change its structure (which produces its behavior). The use of DCSYM provides a useful visualized analysis of the structure and operation of the system in depth while pointing out the parts that can be improved.

The use of VENSIM and the modeling of the main production process leads to the extraction of useful information and knowledge about the project, but also generally about any system that we want to analyze. The aim is to create a model that is as close as possible to the real aspects of our system, a realistic simulation model that will capture the causal-effect relationship and will be able to simulate the behavior of the system under consideration. It should describe the structure (static elements) and the state (dynamic elements) of the system through the system state equations, which correlate the parameters of the model with the inputs to produce outputs.

The study of the behavior of a system, using the model we have created, should first be done by testing hypotheses or theories about system in-focus behavior and predicting or estimating its future behavior.

Finally, it should be as accessible and simple as possible to reduce complexity rather than increase it (KISS).

\section{References}

Ackoff, R., (1999), "Ackoff's Best: His Classic Writings on Management", John Wiley \& Sons, New York

Ashby, R. (2015), "Introduction to Cybernetics", Martino Fine Books, Eastford 
Assimakopoulos, N., Theocharopoulos, I. (2009), "The Design and Control Systemic Methodology (DCSYM): a multi-agent modelling and operation platform", International Journal of Applied Systemic Studies 2009 - Vol. 2, No.3, p. 193 - 217

Beer, S. (2008). "Diagnosing The System For Organisations", Wiley, Chichster, England

Beer, S. (1979), "The Heart of Enterprise", Wiley, Chichester, England

Bertalanffy, L., (1969), "General System Theory: Foundations, Development, Applications", Revised Edition, Penguin University Books, New York

Espejo, R., Harnden, R., (1992), "The Viable System Model: Interpretations and Applications of Stafford Beer's VSM", Wiley, Chichester, England

Forrester, J., (2013), "Industrial Dynamics Hardcover", Martino Fine Books, Eastford Ovum Report, (1996), "Market Survey of Document Management Trends", Ovum Publication

Sutton, M., (1996), "Document Management for the Enterprise: Principles, Techniques, and Applications", Wiley, Chichester, England 